\title{
Mechanotransduction of pulsatile stretch in a cell culture model of cardiac hypertrophy connexin 43 (Cx43) expression S Karl*1, D Rojas Gomez ${ }^{2}$, S Dhein ${ }^{2}$ and A Salameh ${ }^{1}$
}

\begin{abstract}
Address: ${ }^{1}$ Herzzentrum, Kinderkardiologie, Universität Leipzig, Germany and ${ }^{2}$ Herzzentrum, Herzchirurgie, Universität Leipzig, Germany
\end{abstract} * Corresponding author

from 12th Joint Meeting of the Signal Transduction Society (STS). Signal Transduction: Receptors, Mediators and Genes Weimar, Germany. 29-31 October 2008

Published: 26 February 2009

Cell Communication and Signaling 2009, 7(Suppl I):AI8 doi:I0.II86/I478-8IIX-7-SI-AI8

This abstract is available from: http://www.biosignaling.com/content/7/SI/AI8

(c) 2009 Karl et al; licensee BioMed Central Ltd.

\section{Introduction}

In the heart gap junction intercellular coupling represents the fundament of proper electrical propagation. In cardiac hypertrophy up-regulation of $\mathrm{Cx} 43$ has been observed and was suggested as being related to sudden cardiac death. It has been found, that expression and distribution of $\mathrm{Cx} 43$, which is the main gap junction forming connexin in the ventricle, is altered in many pathological conditions. We therefore wanted to elucidate whether exposure of cardiomyocytes to chronic pulsatile stretch affects $\mathrm{Cx} 43$ and whether mechanotransduction pathways interfere with adrenergic regulation of $\mathrm{Cx} 43$, already shown in former experiments.

\section{Results}

Neonatal rat cardiomyocytes cultured on gelatine coated Flex Cell cell culture plates were exposed to pulsatile stretch $(110 \%$ of resting length, $1 \mathrm{~Hz})$ for 24 hours without stimulation of adrenoceptors or in presence of $0,1 \mu \mathrm{M}$ isoproterenol (Iso) for beta-adrenoceptor stimulation or $0,1 \mu \mathrm{M}$ phenylephrine (Phe) for alpha1-adrenoceptor stimulation. Cx43-expression was determined by Western blotting. Exposure to pulsatile stretch led to a significant increase in Cx43 protein expression $(157 \pm 6 \%)$, as did treatment with Iso $(147 \pm 6 \%)$ or Phe $(176 \pm 16 \%)$. Combined stimulation by stretch and Iso or stretch and Phe lead to only minor further increase in Cx43-levels (Iso+Stretch: $166 \pm 16 \%$, Phe+Stretch: $191 \pm 17 \%$ ). To elucidate the further signal transduction cascade we investigated phosphorylation of extracellular regulated kinase (ERK1/2) and glycogen synthase kinase 3-beta (GSK3beta). Exposure to pulsatile stretch led to a significant increase of phosphorylation of ERK1 $(143 \pm 6 \%)$, ERK2 $(159 \pm 5 \%)$ and GSK3-beta $(138 \pm 7 \%)$ as did treatment with Iso and Phe. Again a significant further increase in these levels by addition of both stimuli could not be observed.

\section{Conclusion}

Thus, pulsatile stretch affects cardiac gap junction expression and leads to phosphorylation of MAP kinases (= activation) and of GSK3-beta (= inactivation). There were only small additive effects with adrenergic stimulation indicating a possible ceiling effect in up-regulation of Cx43 expression maybe caused by counter regulative mechanisms. 